\title{
Erratum to: A study on the competition between bias-induced charge trapping and light-induced instability in In-Ga-Zn-O thin-film transistors
}

\author{
Jozeph Park ${ }^{1,2}$ • Nguyen Dinh Trung ${ }^{3}$ • Yang Soo Kim ${ }^{3}$. Jong Heon Kim ${ }^{3}$. \\ Kyung Park ${ }^{4} \cdot$ Hyun-Suk Kim ${ }^{3}$
}

Published online: 31 May 2016

(C) Springer Science+Business Media New York 2016

Erratum to: J Electroceram

DOI: $10.1007 / \mathbf{s} 10832-016-0032-3$

The name of the third author should be displayed as Yang Soo

Kim (as shown above), not Soo Kim Yang.

The original article was corrected.

The online version of the original article can be found at http://dx.doi.org/ 10.1007/s10832-016-0032-3.

Jozeph Park jozeph.park@gmail.com

$\triangle$ Hyun-Suk Kim khs3297@cnu.ac.kr

1 Department of Materials Science and Engineering, KAIST, Daejeon 305-338, Republic of Korea

2 Present address: R\&D Center, Samsung Display, Yongin-Si, Republic of Korea

3 Department of Materials Science and Engineering, Chungnam National University, Daejeon 305-764, Republic of Korea

4 School of Integrated Technology, Yonsei University, Incheon 406-840, Republic of Korea 